\title{
Expression of cytokeratin-19 (CK19) in the classical subtype of papillary thyroid carcinoma: the experience of one center in the Silesian region
}

\author{
Krzysztof Kaliszewski ${ }^{1}$, Dorota Diakowska ${ }^{2}$, Marta Strutynska-Karpinska ${ }^{2}$, \\ Marta Rzeszutko ${ }^{3}$, Jedrzej Grzegrzolka ${ }^{4}$, Piotr Dziegiel, \\ Beata Wojtczak ${ }^{1}$, Krzysztof Sutkowski ${ }^{1}$
}

${ }^{1} 1{ }^{\text {st }}$ Department and Clinic of General, Gastroenterological, and Endocrine Surgery, Wroclaw Medical University, Wroclaw, Poland

${ }^{2}$ Department and Clinic of Gastrointestinal and General Surgery, Wroclaw Medical University, Wroclaw, Poland

${ }^{3}$ Department of Pathomorphology, Wroclaw Medical University, Wroclaw, Poland

${ }^{4}$ Department of Histology and Embryology, Wroclaw Medical University, Wroclaw, Poland

\begin{abstract}
Introduction. Cytokeratin-19 (CK19) is recognized as a reliable tumor marker of papillary thyroid carcinoma (PTC). The general prognosis in the classical subtype of PTC (CSTPTC) remains favorable, but some cases can be very aggressive. The aim of this study was to evaluate the localization and intensity of immunohistochemical CK19 expression in CSTPTC and its associations with the clinical and pathological characteristics of patients with CSTPTC in the Silesian region.

Material and methods. All the available clinical and histopathological data for 149 patients with CSTPTC from the Silesian region were retrospectively analyzed. The group consisted of $135(90.6 \%)$ women and $14(9.4 \%)$ men (mean age and SD: $52.3 \pm 15.0$ ). All these patients with CSTPTC underwent surgery at the same center between 2008 and 2013; the follow-up period was 24 to 90 months (mean and SD: $47 \pm 20$ ).

Results. In 142 (95.3\%) of the patients with CSTPTC, positive cytoplasmic staining of CK19 was found. A higher expression of CK19 was observed in the group of patients without the recurrence of the disease $(p=0.015)$. CK19 expression was not associated with age, gender, tumor focality, disease stage, tumor size (pT), lymph node involvement $(\mathrm{pN})$, or distant metastases $(\mathrm{pM})$.

Conclusions. Decreased CK19 expression in CSTPTC cases with relapse suggests that it plays a role in the carcinoma progression of CSTPTC. The association between lower CK19 expression and patients' unfavorable postoperative course could suggest its possible role as a marker of CSTPTC poor prognosis. (Folia Histochemica et Cytobiologica 2016, Vol. 54, No. 4, 193-201)
\end{abstract}

Key words: papillary thyroid carcinoma; cytokeratin 19; prognosis; IHC

Correspondence address: K. Kaliszewski, M.D.

$1^{\text {st }}$ Department and Clinic of General, Gastroenterological, and Endocrine Surgery

Wroclaw Medical University

Sklodowskiej-Curie St. 66, 50-369 Wroclaw, Poland

tel.: +48717842162

e-mail:krzysztofkali@wp.pl

\section{Introduction}

Thyroid carcinoma is the most common endocrine malignant tumor, and in recent decades, its incidence has considerably increased [1-3]. This type of malignancy occurs twice as often in Caucasian people as in Black, but the highest rates occur among patients from Southeast Asia [4]. The incidence of this tumor in Poland is also increasing [5]. It accounts for $2.6 \%$ of all oncological diseases in women and $0.5 \%$ in men [5]. 
The majority of thyroid carcinomas arise from follicular cells and, although patients generally have good survival rates and postsurgical prognosis, sometimes these thyroid tumors take a very aggressive course. For this reason, the main goal of recent studies has been to improve the accuracy of the current diagnostic tools so as to identify those tumors with aggressive features [1-3]. Many clinical and pathological factors are associated with poor prognosis of thyroid carcinoma [6]. The most frequently used are age, gender, distant metastases, lymph node involvement, histopathological subtypes, greater size of primary tumor, and multifocality [6].

In turn, papillary thyroid carcinoma (PTC) is the most common thyroid malignancy, accounting for 80-90\% of all thyroid malignant tumors [7-9]. As with thyroid carcinomas in general, the prognosis of PTC is favorable, and the ten-year survival rate of the classical subtype of PTC (CSTPTC) is over 90\% [9]. CSTPTCs may also be very aggressive, as demonstrated by the recurrence of the disease. Environmental, genetic, immunological, and hormonal factors are considered possible pathomechanisms for thyroid malignancy recurrence $[10,11]$.

Besides hematoxylin and eosin staining for evaluating thyroid tumor morphology, immunohistochemical (IHC) methods have been widely used [1,2]. IHC markers are of two types: those related to proteins present in normal thyrocytes (such as thyroglobulin and thyroid transcription factor-1) and those related to proteins in pathological thyrocytes (such as cytokeratin-19, thyroid peroxidase, and Hector Battifora mesothelial epitope-1) [12]. Cytokeratins (CKs) are a family of intermediate filaments of epithelial cells. In cytoplasm, CK filaments form a specific network connecting the cell membrane with the nucleus, serving to position and anchor the nucleus within the cell. Apart from their mechanical role as components of the cytoskeleton, CKs also participate in cellular processes such as mitosis, the postmitotic period, cell movement, differentiation, and apoptosis [13].

There are two types of cytokeratins: the acidic cytokeratins and the neutral and basic cytokeratins [14]. Both include specific subsets of cytokeratins, which are numbered from 1 to 20 . The acidic type is represented by cytokeratins $9-20$, and the neutral and basic type are numbered from 1 to 8 [14].

The expression of some cytokeratins is often tissue-specific or organ-specific, and these differences also apply to various malignancies [14]. CK profiles have thus been widely determined by immunohistochemistry for the diagnosis and characterization of malignant tumors [15].

Among the acidic cytokeratins is cytokeratin 19 (CK19), which is composed of approximately 400 ami- no acids and has a molecular weight of $40 \mathrm{kDa}$. The human gene encoding CK19 is localized on chromosome 17q21-22 [16, 17]. Some authors have suggested that, during cell differentiation, CK19 can be regarded as a universal cytokeratin, because it can form dimers with any cytokeratin from the second group [18]. Soluble fragments of CK19 can be detected with ELISA using the CYFRA 21-1 assay [19]. CK19 is observed in the ductal epithelium of the pancreas and bile duct, and very often is considered a biomarker of hepatocellular carcinoma, PTC, squamous cell carcinoma, and large bowel adenocarcinoma [20-23]. Jain et al. [24] pointed to CK19 as an independent prognostic factor for neuroendocrine tumors of the pancreas. High levels of expression of CK19 in thyroid carcinoma have been described not only in humans, but also in animals [25]. Ciaputa et al. described the strong positive immunoreactivity of CK19 in a vesicular-compact type of thyroid carcinoma in dogs [25].

Positive CK19 staining has been observed in papillary thyroid cancer (PTC), and is recognized as a reliable tumor marker of PTC [12, 26, 27]. In particular, IHC staining of CK19 has been found to be an accurate marker in diagnosing malignancy in thyroid nodules through the immunoreactivity of CK19 in cells obtained during the fine needle aspiration biopsy procedure [28].

The most common subtypes of PTC include the classic (CSTPTC), follicular, and tall-cell variants [29]. However, many other uncommon variants of PTC have also been described, including oncocytic and columnar cell variants, diffuse sclerosing and solid forms, clear cell and cribriform-morular variant [29]. In 2010, Asioli et al. [30] described another very rare variant of PTC which they called "PTC with prominent hobnail features". However, the usefulness of CK19 as a postsurgical prognostic factor of CSTPTC in various populations is so far unknown or controversial [31, 32]. The aim of our study was thus to investigate relationships between the intensity of CK19 expression at the time of diagnosis of CSTPTC and its clinical and pathological characteristics - and particularly the postsurgical outcomes in patients in the Silesian region of Poland.

\section{Material and methods}

The study was approved by the Bioethics Committee of Wroclaw Medical University, Poland (number: KB-419/2015).

Patients. The study was performed on 149 archival paraffin blocks of 149 histologically diagnosed CSTPTC cases. All patients had been treated surgically at the Department and Clinic of General, Gastroenterological, and Endocrine Sur- 
gery at Wroclaw Medical University, Poland. At the time of diagnosis and treatment, the majority of patients were in the very initial stages of the disease (132 patients, $88.59 \%$ of the total, in stage I or II); however, there were $15(10.06 \%)$ and $2(1.34 \%)$ patients in stages III and IV, respectively. All individuals underwent the standard total thyroidectomy with central lymphadenectomy. The surgical tissue specimens were fixed in $10 \%$ buffered formalin and diagnosed histopathologically at the Department of Pathomorphology, Wroclaw Medical University, Poland. All available clinical and pathological data, along with the postoperative specimens from the 149 patients, were retrospectively examined (Table 1). The group consisted of 135 (90.6\%) women and 14 (9.4\%) men. The mean age was $52.3 \pm 15.0$ years. The time of the follow up was 24 to 90 months (mean and SD: $47 \pm 20$ months). All patients $(100 \%)$ have survived the follow up period.

Histopathological examination and analysis of IHC. H\&E sections were evaluated by two independent pathologists to confirm the diagnosis and to assess whether the CSPTC was unifocal or multifocal. All cases represented classical forms of papillary thyroid carcinoma without any histological variants. The microscopic diagnosis of PTC was based on nuclear features: enlargement, overlapping, irregularity of nuclear contours, grooves, clearing, a ground-glass appearance, nuclear pseudoinclusions, the presence of ovoid cell nuclei, and psammoma bodies. Additionally, papillary carcinomas with classical-type features revealed characteristic papillary architecture, pure or admixed with follicles in variable proportion.

Immunohistochemistry. Archival paraffin tissue blocks were used to obtain $4 \mu \mathrm{m}$-thick sections that were transferred onto adhesive slides, deparaffinized in xylene, rehydrated in graded ethanol, and washed in water and phosphate-buffered saline (PBS). Slides were immunostained in an autostainer (Dako, Glostrup, Denmark) with monoclonal antibodies directed against the CK19 antigen (CK19, clone RCK108, Dako). The IHC technique was performed using the EnVision FLEX method (Dako), using the chromogen 5',5'-diaminobenzidine (DAB) as a substrate. Finally, all slides were counterstained with Mayer's hematoxylin (Dako). Appropriate positive and negative controls were prepared. The positive control for CK19 was skin (epidermis). The negative controls were carried out by replacing the primary antibody with PBS. A positive membranous expression with or without cytoplasmic staining of neoplastic cells qualified the case as positive for CK19.

All immunostainings were evaluated by two pathologists using an Olympus BX-41 light microscope (Olympus, Tokyo, Japan), and the immunohistochemical reaction was scored using the so-called Allred score, which is the sum of the percentage score (percentage of immunopositive cells) and the staining intensity score (labeling intensity) [32].
Table 1. Demographic, clinical, and histopathological characteristics of patients with the classical subtype of papillary thyroid carcinoma (CSPTC)

\begin{tabular}{|c|c|}
\hline Parameter & Average \pm SD or number $(\%)$ \\
\hline \multicolumn{2}{|l|}{ Gender } \\
\hline Females & $135(90.6 \%)$ \\
\hline Males & $14(9.4 \%)$ \\
\hline \multicolumn{2}{|l|}{ Age (years) } \\
\hline All patients & $52.3 \pm 15.0$ \\
\hline Female & $52.1 \pm 15.1$ \\
\hline Male & $55.5 \pm 15.3$ \\
\hline \multicolumn{2}{|l|}{ Age } \\
\hline \multicolumn{2}{|l|}{ All patients: } \\
\hline$<45$ & $44(29.5)$ \\
\hline$\geq 45$ & $105(70.5)$ \\
\hline \multicolumn{2}{|l|}{ Female: } \\
\hline$<45$ & $41(30.4)$ \\
\hline$\geq 45$ & $94(69.6)$ \\
\hline \multicolumn{2}{|l|}{ Male: } \\
\hline$<45$ & $3(21.4)$ \\
\hline$\geq 45$ & $11(78.6)$ \\
\hline \multicolumn{2}{|l|}{ Unifocal or multifocal PTC } \\
\hline Unifocal & $141(94.6)$ \\
\hline Multifocal & $8(5.4)$ \\
\hline \multicolumn{2}{|l|}{ Recurrence } \\
\hline Nonrecurrence & $136(91.3)$ \\
\hline Recurrence & $13(8.7)$ \\
\hline \multicolumn{2}{|l|}{ pTNM* } \\
\hline I & $113(75.8)$ \\
\hline II & $19(12.8)$ \\
\hline III & $15(10.1)$ \\
\hline IV & $2(1.3)$ \\
\hline \multicolumn{2}{|l|}{ pT } \\
\hline pT1a & $52(34.9)$ \\
\hline pT1b & $63(42.3)$ \\
\hline pT2 & $26(17.4)$ \\
\hline pT3 & $7(4.7)$ \\
\hline pT4 & $1(0.7)$ \\
\hline \multicolumn{2}{|l|}{$\mathrm{pN}$} \\
\hline pNo & $125(83.9)$ \\
\hline pN1a & $21(14.1)$ \\
\hline $\mathrm{pN} 1 \mathrm{~b}$ & $3(2.0)$ \\
\hline \multicolumn{2}{|l|}{ M } \\
\hline pM0 & $148(99.3)$ \\
\hline pM1 & $1(0.7)$ \\
\hline \multicolumn{2}{|l|}{ Cytokeratin 19 expression } \\
\hline Positive & $142(95.3)$ \\
\hline Negative & $7(4.7)$ \\
\hline
\end{tabular}

*TNM classification according to pTNM staging [43].

A proportional score was assigned representing the estimated proportion of positive, immunoreactive tumor cells $(0$ : none; $1:<1 / 100 ; 2:>1 / 100$ but less than $1 / 10 ; 3:>1 / 10$ but less than $1 / 3 ; 4:>1 / 3$ but less than $2 / 3 ; 5:>2 / 3$ ). Average 


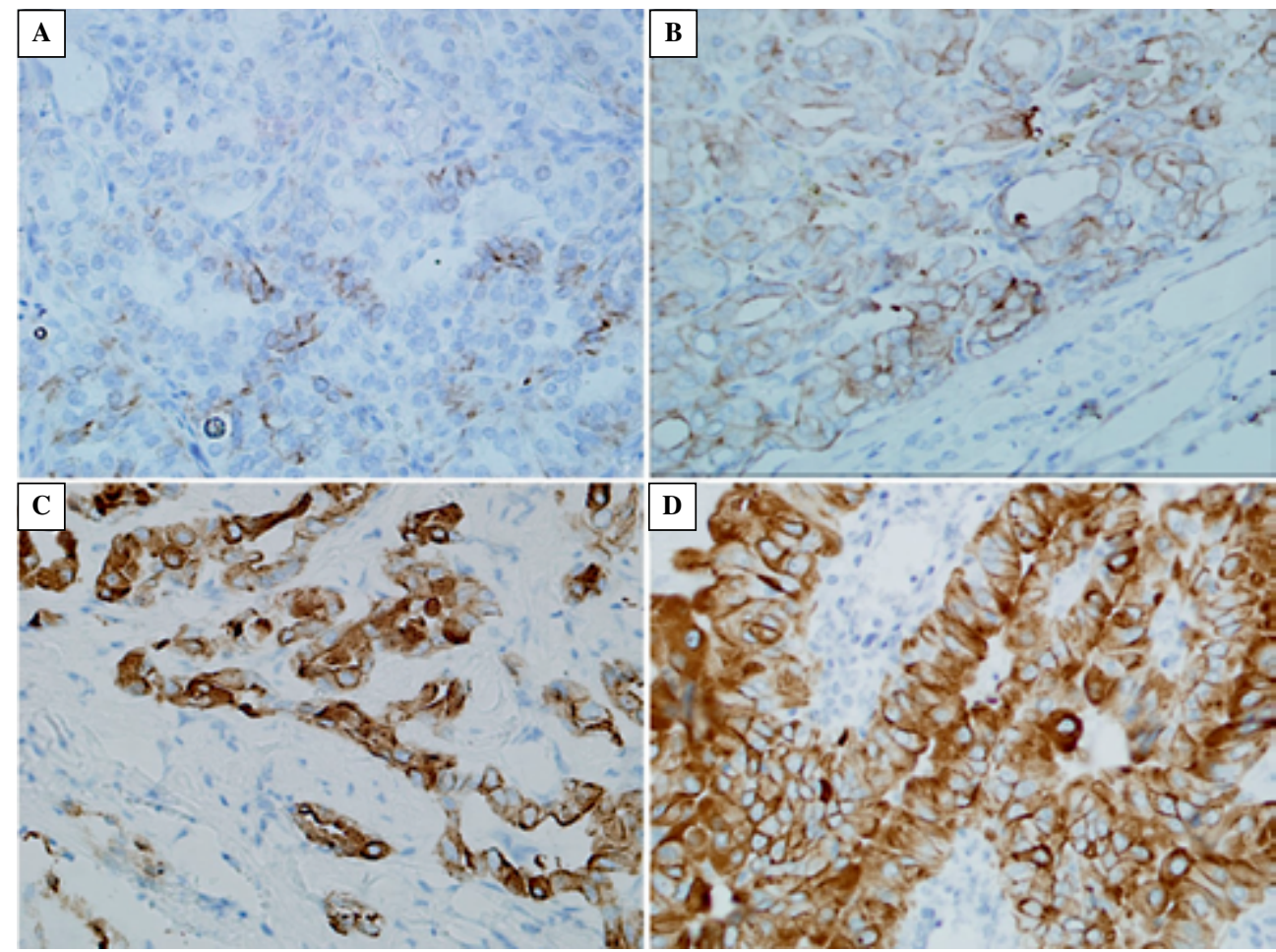

Figure 1. CK19 expression in papillary thyroid carcinoma. Immunohistochemical staining was performed as described in Material and methods. Immunoreactivity was observed in the cytoplasm and cell membrane of carcinoma cells. A, B. Weak cytoplasmic expression; C, D. Strong cytoplasmic expression. Magnification $\times 400$.

estimated intensity of immunostaining was assigned an intensity score (0: none; 1 : weak; 2 : intermediate; 3 : strong). The proportional score [PS] and the intensity score [IS] were added to obtain total score [TS], ranging from 0 to 8 . Sections with Allred scores of $\leq 2$ were considered negative while those with Allred scores $\geq 3$ were taken as positive.

Statistical analysis. All the statistical analysis was performed using Prism 5.0 (GraphPad, CA, USA) and Statistica 10 (StatSoft Inc., Tulsa, OK, USA) software. The type of variable distribution was determined using the Shapiro-Wilk normality test. To analyze the correlations of CK19 expression with the clinical and pathological data chi-square test, the Fisher exact test or the Spearman correlation test were used. The Mann-Whitney $U$-test and the Kruskal-Wallis test were used to compare the differences in CK19 expression according to Allred score. To analyze the Recurrence Free Survival period, the Kaplan-Meyer curve was obtained and the Mantel-Cox test was employed. Univariate and multivariate Cox analysis of survival was also performed. The results were considered statistically significant at $\mathrm{p}<0.05$.

\section{Results}

The immunoreactivity of CK19 was noted in the cytoplasm and cell membranes of the papillary thyroid carcinoma cells (Figure 1). The demographic, clinical, and histopathological characteristics of the patients with CSPTC are presented in Table 1. One hundred and forty-nine patients - of which $135(90.6 \%)$ were females and $14(9.4 \%)$ males - with a diagnosis of CSPTC were evaluated. The mean age was 52.3 years $( \pm 15.0)$. The majority of patients had unifocal PTC (141 individuals, $94.6 \%)$. Thirteen $(8.7 \%)$ individuals presented recurrence of PTC in the follow-up period. The majority of patients at the time of diagnosis and treatment were in the earlier stages of the disease (pT1a or pT1b: 115 patients, $77.2 \%$ ); however, there were $7(4.7 \%)$ and $1(0.7 \%)$ patients in stages pT3 and pT4, respectively. In the case of $24(16.1 \%)$ and $1(0.7 \%)$ individuals, lymph node and distant metastases, respectively, were observed. In $95.3 \%$ of examined CSTPTC cases, we observed positive cytoplasmic staining of CK19 (Table 1).

As shown in Table 2, the intensity of CK19 immunostaining did not correlate with age $(p=0.570)$, gen$\operatorname{der}(p=0.157)$, tumor focality $(p=0.511)$, disease stage at the time of diagnosis $(\mathrm{p}=0.423)$, tumor size $(\mathrm{pT}$; $\mathrm{p}=0.692)$, lymph node involvement $(\mathrm{pN} ; \mathrm{p}=0.196)$, or distant metastases $(\mathrm{pM} ; \mathrm{p}=1.0)$. However, we found significantly higher expression of CK19 in patients who survived the entire follow-up period without recurrence $(p=0.015$, Mann-Whitney test; Figure 2). In addition, 
Table 2. Intensity of cytokeratin-19 (CK19) expression in relation to the clinical and pathological parameters in patients with the classical subtype of PTC $(\mathrm{n}=149)$

\begin{tabular}{|c|c|c|c|c|}
\hline Parameter & CK19 expression positive/negative & p-value ${ }^{1}$ & CK19 intensity median (min, max) & p-value ${ }^{2}$ \\
\hline \multicolumn{5}{|l|}{ Gender } \\
\hline Female & $128 / 7$ & 0.494 & $5(0,8)$ & 0.157 \\
\hline Male & $14 / 0$ & & $3(1,7)$ & \\
\hline \multicolumn{5}{|l|}{ Age } \\
\hline \multicolumn{5}{|l|}{ Total group: } \\
\hline$<45$ & $41 / 3$ & 0.340 & $4(0,8)$ & 0.570 \\
\hline$\geq 45$ & $101 / 4$ & & $2+(0,8)$ & \\
\hline \multicolumn{5}{|l|}{ Female: } \\
\hline$<45$ & $38 / 3$ & 0.460 & $2(0,3)$ & 0.523 \\
\hline$\geq 45$ & $90 / 4$ & & $2(0,3)$ & \\
\hline \multicolumn{5}{|l|}{ Male: } \\
\hline$<45$ & $3 / 0$ & 1.000 & $2(1,3)$ & 0.437 \\
\hline$\geq 45$ & $11 / 0$ & & $1(1,3)$ & \\
\hline \multicolumn{5}{|c|}{ Unifocal or multifocal PTC } \\
\hline Unifocal & $135 / 6$ & 0.326 & $5(0,8)$ & 0.511 \\
\hline Multifocal & $7 / 1$ & & $6.5(0,8)$ & \\
\hline \multicolumn{5}{|l|}{ Recurrence } \\
\hline Nonrecurrence & $129 / 7$ & 0.521 & $5(0,8)$ & $0.015 *$ \\
\hline Recurrence & $13 / 0$ & & $2(1,8)$ & \\
\hline \multicolumn{5}{|l|}{ pTNM } \\
\hline I & $106 / 7$ & 0.505 & $5(0,8)$ & 0.423 \\
\hline II & $19 / 0$ & & $5(2,8)$ & \\
\hline III & $15 / 0$ & & $4(1,8)$ & \\
\hline IV & $2 / 0$ & & $1.5(1,2)$ & \\
\hline \multicolumn{5}{|l|}{ pT } \\
\hline pT1a & $51 / 1$ & 0.591 & $5(0,8)$ & 0.692 \\
\hline pT1b & $58 / 5$ & & $4(0,8)$ & \\
\hline pT2 & $25 / 1$ & & $5.5(0,8)$ & \\
\hline pT3 & $7 / 0$ & & $5(1,8)$ & \\
\hline pT4 & $1 / 0$ & & $2(2)$ & \\
\hline \multicolumn{5}{|l|}{$\mathrm{pN}$} \\
\hline pN0 & $118 / 7$ & 0.494 & $2+(0,3+)$ & 0.196 \\
\hline pN1a & $21 / 0$ & & $1+(1+, 3+)$ & \\
\hline $\mathrm{pN} 1 \mathrm{~b}$ & $3 / 0$ & & $1+(1+, 1+)$ & \\
\hline \multicolumn{5}{|l|}{$\mathrm{pM}$} \\
\hline pM0 & $141 / 7$ & 0.953 & $5(0,8)$ & 1.000 \\
\hline pM1 & $1 / 0$ & & $1(1)$ & \\
\hline
\end{tabular}

p-value ${ }^{1}$ — chi-square test with exact Fisher test; p-value ${ }^{2}$ — Mann-Whitney or Kruskal-Wallis tests; PTC — papillary thyroid carcinoma; *statistically significant difference.

Recurrence Free Survival analysis showed that patients with negative [7 (4.7\%)] or low expression of CK19 lived without recurrence significantly shorter than did patients with moderate or high CK19 expression ( $p<0.05$, Mantel-Cox test; Figure 3). Univariate and multivariate Cox analysis of survival shows Table 3.

\section{Discussion}

It is estimated that about $20 \%$ of patients with PTC at the time of diagnosis and treatment had lymph node metastases, and the same number of patients had a more aggressive disease course, with early recurrence of the tumor [33]. Because of this, very accurate markers, which can predict the worse prognosis, even with early treatment, are crucial for clinical management.

Some authors have suggested that conventional, histopathological, and immunohistochemical diagnostic methods play an important role in providing a definitive diagnosis and therapeutic guidance [20, 34]. Some biomarkers, such as thyroperoxidase, cytokeratins, galectin-3, and Hector Battifora mesothelial 


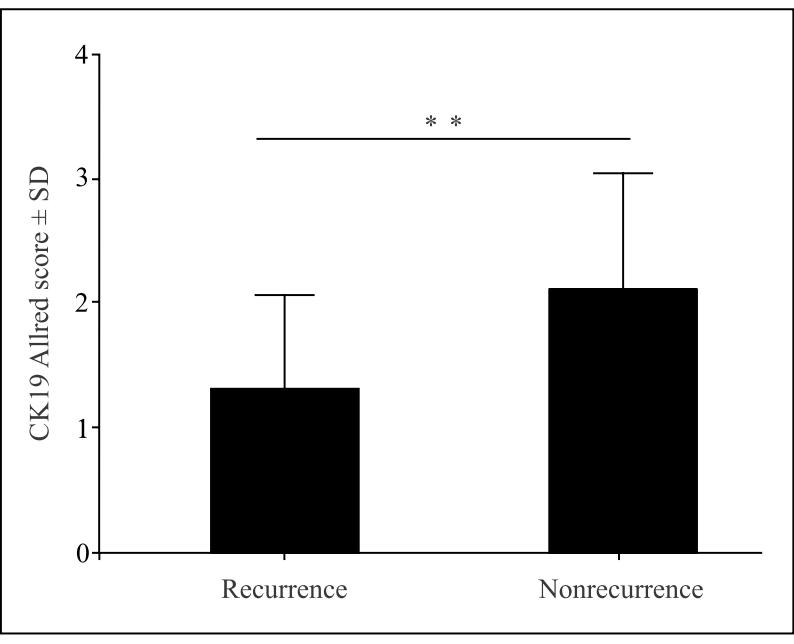

Figure 2. Immunoexpression of cytokeratin 19 (CK19) in the recurrent and nonrecurrent group of papillary thyroid carcinoma patients. ${ }^{*} \mathrm{p}=0.0148$ (Mann-Whitney test).

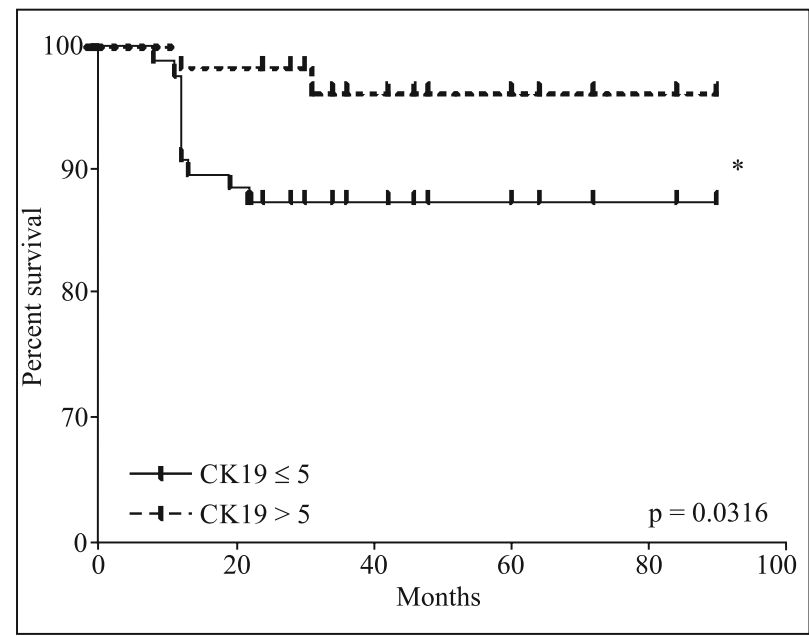

Figure 3. Survival analysis for patients with the classical subtype of papillary thyroid carcinoma (CSPTC) with CK19 cytoplasmic expression in carcinoma cells. Patients with higher CK19 expression in carcinoma cells lived without recurrence of the disease significantly longer than did patients with lower expression of CK19. * $\mathrm{p}<0.05$, Mantel-Cox test.

epitope-1, have some significance in differentiating thyroid carcinomas and have been widely described $[20,35,36]$. However, their value as prognostic factors of the aggressive course of PTC has not been clearly established [2, 20, 34-36]. Knowledge of high aggressiveness in PTC and the high probability of its early recurrence - even after early primary surgical treatment - may improve the effectiveness of further treatment.
Nearly sixty years ago, Bjorklund proposed CK19 as a possible marker for epithelial tumors [37]; fifty years later, Uenishi et al. [21] showed that the incidence of extrahepatic disease, such as lymph node metastases, in patients with hepatocellular carcinomas was significantly higher in those with positive expression of CK19. They concluded that positive CK19 expression was a predictor of early postoperative recurrence, due to increased invasiveness. Song et al. [38] clearly established that the immunohistochemical expression of CK19 in PTC allowed nonmalignant thyroid lesions to be distinguished from PTC, which demonstrated diffuse and strong cytoplasmic CK19 staining; however, they did not describe any correlation between CK19 cytoplasmic staining and postoperative course. Very similar results were obtained by Lam et al. [39]. In their study of 153 thyroid carcinoma cases, strong, diffuse staining of CK19 was observed in more than $80 \%$ of PTC cases, while focal staining was seen in more than $60 \%$ of follicular thyroid carcinomas. In agreement with the previous reports [38, 39], we observed positive CK19 expression in almost all (95.3\%) patients with CSTPTC. In 47 (31.5\%), the staining was weak; in $41(27.5 \%)$ medium; and in $54(36.3 \%)$ strong. Only in $7(4.7 \%)$ CSTPTC cases did we see no CK19 expression.

Calangiu et al. [40] provided some new information on the usefulness of CK19 in differentiating the classical and follicular papillary carcinomas and the tall-cell variant of PTC. They observed higher CK19 immunostaining in the classical and follicular types; however, they did not analyze the correlation of CK19 immunostaining with the postsurgical course of the patients. Liu et al. [41] investigated the correlation between CK19 expression and the aggressive behavior of PTC. They showed that the expression of CK19 did not have any association with capsular invasion or lymph node metastases. They also did not consider the postoperative course of their patients in terms of CK19 expression [41].

In our study, we found the significant correlation of the lower intensity of CK19 expression with a worse prognosis of CSTPTC postsurgical course. In our patients, thus was demonstrated as early recurrence. The higher expression of CK19 was correlated with better postsurgical course - that is, the absence of recurrence. Kosacka et al. [42] presented very similar observations; their study was also performed in the Silesian region, but concerned malignancies of other organs. As in the present study, they showed that higher expression of CK19 in non-small cell lung carcinoma correlated with better prognosis in patients after surgical treatment.

The reasons for the discrepancies in CK19 expression and postsurgical course of PTC are not 
Table 3. Univariate and multivariate Cox analysis of survival

\begin{tabular}{|c|c|c|c|c|c|c|}
\hline \multirow[t]{3}{*}{ Characteristics } & \multirow{3}{*}{$\begin{array}{c}\text { Univariate Cox analysis } \\
\text { Overall survival } \\
\text { HR }\end{array}$} & \multicolumn{5}{|c|}{ Multivariate Cox analysis } \\
\hline & & \multicolumn{5}{|c|}{ Overall survival } \\
\hline & & $95 \% \mathrm{CI}$ & P-value & HR & $95 \% \mathrm{CI}$ & P-value \\
\hline $\begin{array}{l}\text { CK19 expression } \\
\text { Positive } \\
\text { Negative } \\
\end{array}$ & 0.139 & $0.038-0.511$ & 0.0293 & 0.245 & $0.053-1.130$ & 0.071 \\
\hline $\begin{array}{l}\text { Age } \\
\quad<45 \\
\geq 45\end{array}$ & 0.648 & $0.209-1.959$ & 0.435 & & & \\
\hline $\begin{array}{l}\text { Gender } \\
\text { Female } \\
\text { Male }\end{array}$ & 1.794 & $0.396-8.128$ & 0.448 & & & \\
\hline $\begin{array}{l}\text { Unifocal or multifocal PTC } \\
\text { Unifocal } \\
\text { Multifocal }\end{array}$ & 1.452 & $\begin{array}{l}0.188- \\
11.170\end{array}$ & 0.720 & & & \\
\hline $\begin{array}{c}\text { pTNM } \\
\text { I } \\
\text { II } \\
\text { III } \\
\text { IV }\end{array}$ & 3.636 & $2.120) 6.238$ & $<0.0001$ & 1.743 & $0.884-3.436$ & 0.108 \\
\hline $\begin{array}{l}\text { pT } \\
\text { pT1a } \\
\text { pT1b } \\
\text { pT2 } \\
\text { pT3 } \\
\text { pT4 }\end{array}$ & 2.576 & $1.537-4.317$ & 0.0003 & 0.507 & $0.897-2.534$ & 0.120 \\
\hline $\begin{array}{l}\mathrm{pN} \\
\mathrm{pN} 0 \\
\mathrm{pN} 1 \mathrm{a} \\
\mathrm{pN} 1 \mathrm{~b} \\
\end{array}$ & 10.763 & $\begin{array}{l}4.897- \\
23.657\end{array}$ & $<0.0001$ & 4.244 & $\begin{array}{l}1.438- \\
12.518\end{array}$ & 0.0088 \\
\hline $\begin{array}{l}\mathrm{pM} \\
\mathrm{pM} 0 \\
\mathrm{pM} 1\end{array}$ & 18.295 & $\begin{array}{c}2.289- \\
146.225\end{array}$ & 0.0061 & 2.460 & $\begin{array}{l}0.210- \\
28.774\end{array}$ & 0.473 \\
\hline
\end{tabular}

Bold — statistically significant values; CI — confidence interval; PTC - papillary thyroid carcinoma.

clear. Possible explanations include geographical differences; however, a more reasonable explanation could be related to the pathogenic mechanism in thyroid carcinogenesis: the tumor cells express CK19 at the beginning of the malignant process, but perhaps they lose these proteins during the progression of carcinogenetic process.

In our study, the intensity of CK19 expression did not correlate with age, gender, disease stage, primary tumor dimension, multifocality, or lymph node metastases. However, we confirmed the hypothesis that there was a correlation between the intensity of CK19 expression in immunohistochemical staining and the postsurgical course of CSTPTC. Our compositional data analysis offers a novel analytic approach for immunohistochemical studies, providing greater insight into the differences in intensity of staining patterns between papillary thyroid carcinomas. CK19 was expressed by tumor cells in almost all patients with CSPTC in the Silesian region. The higher expression of CK19 correlated with favorable postoperative course with no recurrence. We suggest that the low expression of CK19 could be a possible indicative factor for recurrence. However, our study also shows great differences between the numbers of patients diagnosed and treated in the initial stages of the disease (132 $(88.59 \%)$ of patients in stage I or II;) and in the advanced stages, with $15(10.06 \%)$ and $2(1.34 \%)$ individuals, respectively, in stages III and IV. The same situation concerns the recurrence and nonrecurrence subgroups, which contained $136(91.27 \%)$ and $13(8.72 \%)$ patients, respectively. This may affect the statistical analysis. For this reason, our results should be treated as preliminary, and ought to be verified by further studies on larger, more homogenous groups of patients.

\section{References}

1. Tang C, Yang L, Wang N et al. High expression of GPER1, EGFR and CXCR1 is associated with lymph node metastasis in papillary thyroid carcinoma. Int J Clin Exp Pathol. 2014;7:3213-3223. PMID: 26629173. 
2. Wang N, Dong CR, Jiang R et al. Overexpression of HIF-1alpha, metallothionein and SLUG is associated with high TNM stage and lymph node metastasis in papillary thyroid carcinoma. Int J Clin Exp Pathol. 2014;7:322-330. PMID: 24427353.

3. Hambleton C, Kandil E. Appropriate and accurate diagnosis of thyroid nodules: A review of thyroid fine-needle aspiration. Int J Clin Exp Med. 2013;6:413-422. PMID: 23844264.

4. Enewold L, Zhu K, Ron E et al. Rising thyroid cancer incidence in the United States by demographic and tumor characteristics, 1980-2005. Cancer Epidemiol Biomarkers Prev. 2009;18:784-791. doi: 10.1158/1055-9965.EPI-08-0960.

5. Wojciechowska U, Didkowska J. Morbidity and mortality of malignancy in Poland. National Cancer Registry, Maria Skłodowska-Curie Institute of Oncology; 2015. Available at: http://onkologia.org.pl/wp-content/uploads/Rok2012.pdf

6. Lang BH, Lo CY, Chan WF et al. Staging systems for papillary thyroid carcinoma: A review and comparison. Ann Surg. 2007;245:366-378. doi: 10.1097/01.sla.0000250445.92336.2a.

7. Xing M. Molecular pathogenesis and mechanisms of thyroid cancer. Nat Rev Cancer. 2013;13:184-199. doi: 10.1038/ /nrc3431.

8. Liu Z, Wang L, Yi P et al. Risk factors for central lymph node metastasis of patients with papillary thyroid microcarcinoma: a meta-analysis. Int JClin Exp Pathol. 2014;7:932-937.PMID: 24696711.

9. Liu Z, Xun X, Wang Y et al. MRI and ultrasonography detection of cervical lymph node metastases in differentiated thyroid carcinoma before reoperation. Am J Transl Res. 2014;6:147-154. PMID: 24489994.

10. Gurgul E, Kasprzak A, Blaszczyk A et al. Ghrelin and obestatin in thyroid gland: Immunohistochemical expression in nodular goiter, papillary and medullary cancer. Folia Histochem Cytobiol. 2015;53:19-25. doi: 10.5603/FHC.a2015.0004.

11. Vassiliou I, Tympa A, Arkadopoulos N et al. Total thyroidectomy as the single surgical option for benign and malignant thyroid disease: A surgical challenge. Arch Med Sci. 2013;9:74-78. doi: 10.5114/aoms.2013.33065.

12. Liu Z, Yu P, Xiong Y et al. Significance of CK19, TPO, and HBME-1 expression for diagnosis of papillary thyroid carcinoma. Int J Clin Exp Med. 2015;8:4369-4374. PMID: 26064355.

13. Moll R, Franke WW. Intermediate filaments and their interaction with membranes: The desmosome-cytokeratin filament complex and epithelial differentiation. Pathol Res Pract. 1982;175:146-161. doi: 10.1016/S0344-0338(82)80105-2.

14. Quilan RA, Schiller DL, Hatzfeld M et al. Patterns of expression and organization of cytokeratin intermediate filaments. Ann NY Acad Sci. 1985;455:282-306. doi: 10.1111/j.17496632.1985.tb50418.x.

15. Levy G, Purcel K. Premalignant and malignant disorders of the ovaries and oviducts. In: DeCherney A, Nathan L, Goodwin TM, Laufer N, Roman A, ed. Current Diagnosis and Treatment: Obstetrics and Gynecology. Lange: Dong Nai; 2012:848-858.

16. Walid MS, Osborne TJ, Robinson JS. Primary brain sarcoma or metastatic carcinoma? Indian J Cancer. 2009;46:174-175. doi: 10.4103/0019-509X.49160.

17. Bader BL, Jahn L, Franke WW. Low level expression of cytokeratin 8,18 and in vascular smooth muscle cells of human umbilical cord and in cultured cell derived therefrom, with an analysis of the chromosomal locus containing the cytokeratin 19 gene. J Cell Biol. 1988;47:300-319. PMID: 2468493.

18. Stasiak PC, Purkis PE, Leigh IM et al. Keratin 19: predicted amino acid sequence and broad tissue distribution suggest it evolved from keratinocyte keratins. J Invest Dermatol. 1989;92:707-716. PMID: 2469734.
19. Dinets A, Pernemalm M, Kjellin $\mathrm{H}$ et al. Differential protein expression profiles of cyst fluid from papillary thyroid carcinoma and benign thyroid lesions. PLoS One. 2015;10:e126472. doi: 10.1371/journal.pone.0126472.

20. DeLellis R, Lloyd R, Heitz P et al. WHO Classification of Tumours, Pathology and Genetics of Tumours of Endocrine Organs. Lyon: IARC Press; 2004.

21. Uenishi T, Kubo S, Yamamoto T et al. Cytokeratin 19 expression in hepatocellular carcinoma predicts early postoperative recurrence. Cancer Sci. 2003;94:851-857. doi: 10.1111/j.13497006.2003.tb01366.x.

22. Durnez A, Verslype C, Nevens F et al. The clinicopathological and prognostic relevance of cytokeratin 7 and 19 expression in hepatocellular carcinoma: A possible progenitor cell origin. Histopathology. 2006;49:138-151. doi: 10.1111/j. 1365-2559.2006.02468.x.

23. Bhatavdekar JM, Patel DD, Chikhlikar PR et al. Molecular markers are predictors of recurrence and survival in patients with Dukes B and Dukes C colorectal adenocarcinoma. Dis Colon Rectum. 2001;44:523-533. doi: 10.1007/BF02234324.

24. Jain R, Fischer S, Serra S et al. The use of Cytokeratin 19 (CK19) immunohistochemistry in lesions of the pancreas, gastrointestinal tract, and liver. Appl Immunohistochem Mol Morphol. 2010;18:9-15. doi: 10.1097/PAI.0b013e3181ad36ea.

25. Ciaputa R, Nowak M, Kandefer-Gola M et al. Morphological and immunohistological characteristics of follicular-compact thyroid carcinoma in dog. Folia Histochem Cytobiol. 2014;52:157-161. doi: 10.5603/FHC.2014.0009.

26. Bose D, Das RN, Chatterjee U et al. Cytokeratin 19 immunoreactivity in the diagnosis of papillary thyroid carcinoma. Indian J Med Paediatr Oncol. 2012;33:107-111. doi: 10.4103/0971-5851.99746.

27. Sahoo S, Hoda SA, Rosai J et al. Cytokeratin 19 immunoreactivity in the diagnosis of papillary thyroid carcinoma: a note of caution. Am J Clin Pathol. 2001;116:696-702. doi: 10.1309/6D9D-7JCM-X4T5-NNJY.

28. Alexander EK, Kennedy GC, Baloch ZW et al. Preoperative diagnosis of benign thyroid nodules with indeterminate cytology. N Engl J Med. 2012;367:705-715. doi: 10.1056/ NEJMoa1203208.

29. Lloyd RV, Buehler D, Khanafshar E. Papillary thyroid carcinoma variants. Head and Neck Pathology 2011;5:51-56. doi: 10.1007/s12105-010-0236.

30. Asioli S, Erickson LA, Sebo TJ et al. Papillary thyroid carcinoma with prominent hobnail features: A new aggressive variant of moderately differentiated papillary carcinoma. A clinicopathologic immunohistochemical, and molecular study of eight cases. Am J Surg Pathol. 2010;34:44-52. doi: 10.1097/PAS.0b013e3181c46677.

31. Paunovic I, Isic T, Havelka $\mathrm{M}$ et al. Combined immunohistochemistry for thyroid peroxidase, galectin-3, CK19 and HBME-1 in differential diagnosis of thyroid tumors. APMIS. 2012;120:368-379. doi: 10.1111/j.1600-0463.2011.02842.x.

32. Zhu X, Sun T, Lu Het al. Diagnostic significance of CK19, RET, galectin-3 and HBME-1 expression for papillary thyroid carcinoma.JClin Pathol. 2010;63:786-789. doi: 10.1136/jcp.2010.076901.

33. Leboulleux S, Bastholt L, Krause $\mathrm{T}$ et al. Vandetanib in locally advanced or metastatic differentiated thyroid cancer: A randomised, double-blind, phase 2 trial. Lancet Oncol. 2012;13:897-905. doi: 10.1016/S1470-2045(12)70335-2.

34. Cheng S, Serra S, Mercado M et al. A high-throughput proteomic approach provides distinct signatures for thyroid cancer behavior. Clin Cancer Res. 2011;17:2385-2394. doi: 10.1158/1078-0432.CCR-10-2837. 
35. Kaliszewski K, Łukieńczuk T, Dobosz T et al. Analysis of LGALS3BP gene expression in thyroid tissue and peripheral blood lymphocytes in patients with papillary thyroid cancer. Endokrynol Pol. 2006;57:38-44.

36. Wu G, Wang J, Zhou Z et al. Combined staining for immunohistochemical markers in the diagnosis of papillary thyroid carcinoma: Improvement in the sensitivity or specificity? J Int Med Res. 2013;41:975-983. doi: 10.1177/03000605134 90617.

37. Bjorklund B. Antigenicity of pooled human malignant and normal tissues by cytoimmunological technique: Presence of an insoluble heat labile tumour antigen. Int Arch Allergy Appl Immunol. 1957;10:154-184. PMID: 13474809.

38. Song Q, Wang D, Lou Y et al. Diagnostic significance of CK19, TG, Ki67 and galectin-3 expression for papillary thyroid carcinoma in the northeastern region of China. Diagn Pathol. 2011;6:126. doi: 10.1186/1746-1596-6-126.
39. Lam KY, Lui MC, Lo CY. Cytokeratin expression profiles in thyroid carcinomas. Eur J Surg Oncol. 2001;27:631-635. doi: 10.1053/ejso.2001.1203.

40. Calangiu CM, Simionescu CE, Stepan AE et al. The expression of CK19, vimentin and E-cadherin in differentiated thyroid carcinomas. Rom J Morphol Embryol. 2014;55:919-925. PMID: 25329121.

41. Liu Z, Li X, Shi L et al. Cytokeratin 19, thyroperoxidase, HBME-1 and galectin-3 in evaluation of aggressive behavior of papillary thyroid carcinoma. Int J Clin Exp Med. 2014;7:2304-2308. PMID: 25232425.

42. Kosacka M, Jankowska R. [The prognostic value of cytokeratin 19 expression in non-small cell lung cancer] [in Polish]. Pneumonol Alergol Pol. 2007;75:317-323. PMID: 18080980.

43. Edge SB, Compton CC. The American Joint Committee on Cancer: the 7th edition of the AJCC cancer staging manual and the future of TNM.Ann Surg Oncol. 2010;17:1471-1474. doi: 10.1245/s10434-010-0985-4.

Submitted: 14 April, 2016

Accepted after reviews: 13 December, 2016 Available as AoP: 22 December, 2016 